\title{
Spatial Microeconomics: Implications for the Use of Concentration Ratios to Represent Monopoly Power
}

\author{
Bruce L. Benson*
}

The Department of Justice typically uses concentration ratios in antitrust litigations to demonstrate the degree of monopoly power as well as the anticompetitive impact of mergers. ${ }^{1}$ However, the empirical evidence of the link between concentration and competitive performance (i.e., price levels) as well as between concentration and profits, generally shows only a weak relationship, if any at all. ${ }^{2}$ Furthermore, the theoretical foundations of the assumed causal relationship going from concentration of ownership to market power and profits has been challenged. ${ }^{3}$ The typical argument has been that this causal relationship runs from concentration to higher price to profits, generally as a consequence of collusion. An alternative argument stressed by Demsetz [14] and Peltzman [22], is that causality runs from concentration to average cost to profits, as a result of improved production efficiency. The purpose of the following presentation is to add another voice to those challenging regulators' (and a large number of economists') reliance on the assumption of a concentration to a higher collusive price to market power causal relationship. We do so by examining certain implications of spatial price theory. ${ }^{4}$ In particular we shall see that: 1) entry and reduced concentration may lead to higher prices (prices and concentration can be inversely related), 2) the type of spatial competition which involves the largest number of firms in a spatially competitive equilibrium (and therefore the lowest level of concentration), also involves the highest prices, and 3) a merger of spatially separated firms in the same spatially competitive geographic market need not result in higher prices since the spatially competitive price maximizes total profits. Profits cannot rise through collusive price increases. ${ }^{5}$ Thus, the typical argument of concentration to price to profit relationship does not hold in cases where both firms and consumers are spatially dispersed and distance is costly.

\section{THE IMPACT OF ENTRY ON A SPATIAL MONOPOLIST'S PRICE}

Assume we have a single firm located at point $\mathrm{A}$ in Figure 1. This firm is selling a product to spatially dispersed consumers located along the line AB. Consumers must pay the firm's price (mill price) plus delivery costs to their location. Thus, the relevant demand to the spatial monopolist is the aggrega-

*Department of Economics, The Pennsylvania State University, University Park, PA 16802. 


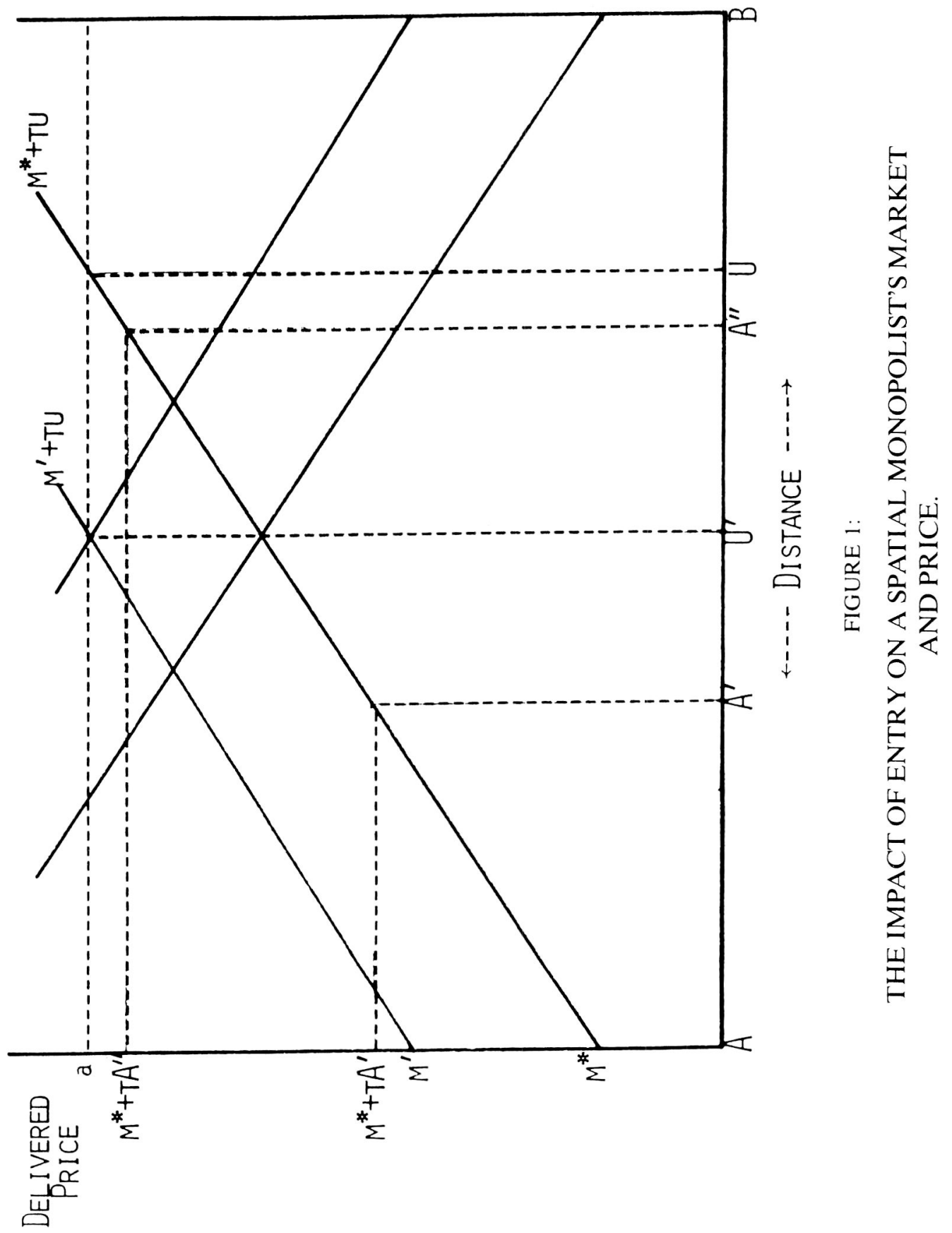


tion of individual demands net of transportation costs. For example, assume that this firm has three consumers located at points A, $\mathrm{A}^{\prime}$, and $\mathrm{A}^{\prime \prime}$ in Figure 1. A fourth potential consumer is located at $B$ but the firm at $A$ does not sell to this individual. We shall see why shortly. Each consumer has an identical linear demand shown by $\mathrm{D}_{1}$ in Figure 2, panel I and given by:

$$
\mathrm{P}=\mathrm{a}-\text { bq. }
$$

The effective demand for the consumer located at $A$ is $D_{1}$, since that individual's purchases do not have to be delivered over any distance. However, the other two consumers must pay transport costs. The full or delivered prices paid by these consumers are

$$
\mathrm{P}=\mathrm{M}+\mathrm{Tu},
$$

where $\mathrm{P}$ is delivered price and the demand price in equation (1), $\mathrm{M}$ is the firm's mill price, and T represents the transport rate per unit of distance $(u)$. Consequently, the effective demand to this firm for the individual located at $\mathrm{A}^{\prime}$ is $\mathrm{D}_{2}$ in Figure 2 since this consumer pays $\mathrm{TA}^{\prime}$ per unit of the product in transportation costs. Curve $\mathrm{D}_{3}$ represents net demand for the consumer located at $\mathrm{A}^{\prime \prime}$ and paying $\mathrm{TA}^{\prime \prime}$ per product unit in transport charges. So, for example, all three consumers are willing to pay delivered price $P_{1}$ for $Q_{1}$ units of output (Figure 2). However, the consumer at $\mathrm{A}^{\prime}$ is willing to pay only $\mathrm{M}_{2}$ to the firm for $Q_{1}$ since $P_{1}-M_{2}=T A^{\prime}$. The individual at $A^{\prime \prime}$ is only willing to pay the firm $M_{3}$ for $Q_{1}$. The potential consumer at $B$ does not buy from the firm at A because his net demand is negative. That is, for the firm at A to sell to this individual, mill price would have to be negative because the transportation costs are so high. Since

$$
\mathrm{P}=\mathrm{M}+\mathrm{Tu}=\mathrm{a}-\mathrm{bq},
$$

the firm's mill price must be less than a $-\mathrm{Tu}$ for the individual to buy a positive quantity.

The relevant demands from the firm's point of view are the demands net of transport costs. These demands show what consumers are willing to pay the firm. Aggregate spatial demand is then the sum of the three net demands $\left(D_{1}\right.$ * in panel (II) of Figure 2). The firm chooses a profit maximizing mill price $\left(\mathrm{M}^{\star}\right)$ by picking an output where marginal cost ( $\mathrm{MC}$ in Figure 2) equals marginal revenue $\left(\mathrm{MR}_{1}\right)$ and each consumer buys the quantities determined from their net demand curve $\left(\mathrm{Q}_{1}{ }^{*}, \mathrm{Q}_{2}{ }^{*}\right.$, and $\mathrm{Q}_{3}{ }^{*}$ in Figure 2, panel I). (Note that $\mathrm{Q}_{1}{ }^{*}+\mathrm{Q}_{2}{ }^{\star}+\mathrm{Q}_{3}{ }^{*}=\mathrm{Q}^{\star}$.) The line $\mathrm{M}^{\star}+\mathrm{Tu}$ in Figure 1 is this monopolist's delivered price schedule.

Now we move to spatial competition. Earlier we assumed that a fourth potential consumer was located at B. Firm A did not sell to this individual because net demand was negative. Now let a new firm enter at B and initially charge a mill price of $M^{\star}$. We can see the impact on firm $A$ by examining Figures 1 and 2. Note that the firm at $B$ now has a lower delivered price to the consumer located at $\mathrm{A}^{\prime \prime}$. Thus, firm A loses that consumer to firm B. The im- 





pact on firm A's aggregate demand is the rotation from $\mathrm{D}_{1}{ }^{*}$ to $\mathrm{D}_{2}{ }^{\prime}$ in Figure 2 panel (II), yielding the price $\mathrm{M}^{\prime}$ in Figure 2. As a result of the loss of its most distant customer, firm $A$ raises its mill price from $\mathbf{M}^{\star}$ to $\mathbf{M}^{\prime}$. Assuming that firm $B$ has the same production costs as firm $A$, the two firms will charge identical prices in equilibrium. Thus, a reduction in ownership concentration leads to higher prices. These results are proven in several places $[2,3,11,12,16,17]$ so they are not formally proven here.

The reason for the increase in mill price following entry comes from the derivation of spatial aggregate demand. The price paid by consumers in spaceless economics equals the price received by the firm. Spatial consumers, however, incur buying costs above the price paid to the seller. Producers are, as a consequence, subject to demand elasticity that relates to the net market price (net of transportation costs), not the total price paid by consumers (delivered price). Elasticity at any given mill price (i.e., $M^{*}$ in Figure 2 ) increases when transport costs are subtracted from the consumer demand. The elasticity of gross demand $\left(D_{1}\right)$ at $M^{*}$ is less than the elasticity of the net demands $\left(D_{2}\right)$ at price $M^{*}$. Demand $D_{3}$, in turn has the greatest elasticity value for any price. Consequently, elasticity of aggregate demand increases at each price as more distant consumers are added. The impact of entry at a distance is to take away the most elastic demand for the original firm. The aggregate demand remaining is, therefore, less elastic than the original demand. The resulting price effect is upward.

This increase in price following entry seems counter-intuitive when your expectations are based on spaceless price theory. An increase in the number of firms should, it seems, lead to lower prices. However, notice two other occurrences. First, additional consumers are being served following entry. Consequently, there is an increase in effective market (as opposed to firm) demand. Furthermore, the individual at $\mathrm{A}^{\prime \prime}$ now pays less in transport costs than he did when he bought this product from A. Again we find an increase in effective demand since there is less transport cost being netted from this consumer's demand. In other words, an increase in the number of spatially dispersed firms increases both supply and demand [4]. The price effect of such a change in spaceless competition is indeterminant unless we specify the relative sizes of the supply and demand changes. ${ }^{6}$ A price increase certainly should not be surprising, however, given this increase in both supply and demand. ${ }^{7}$ When price rises with entry there is an inverse relationship between the level of concentration and the price level - the opposite of what we expect to occur if there is a concentration to price to profit causal relationship.

\section{MODELS OF SPATIAL COMPETITION AND IMPLICATIONS FOR MARKET CONCENTRATION}

The above discussion is of a duopoly situation. An entrepreneurial behavior assumption was implicit to our results (explicit in formal proofs provided elsewhere $[2,3,11,12,16,17])$. That assumption is that the entrepreneur 
believes rival firms will not allow changes in the size of their service areas. ${ }^{x}$ Consequently the entrepreneur, following entry, views his own service area as fixed and prices as a monopolist within that area. This behavioral assumption is generally called Löschian competition, and it is the most common behavioral assumption in the spatial pricing literature. ${ }^{9}$ Other assumptions have been proposed however, and their implications are somewhat different.

Suppose there is a finite linear space of sufficient length to accommodate a large number of firms before all profits disappear. Thus, entry continues beyond the two firm case described above. Given Löschian behavior, linear individual demands, and identical constant marginal costs for all firms, continued entry results in higher and higher prices as the level of concentration falls (see $[2,3,11,12,17]$ for proof). Intuitively the reasoning is still that entry leads to increases in both the number of firms (supply), and in the effective demand being served.

However, it is conceivable that spatial entrepreneurs do not behave as Löschian competitors $[10,11,12,17]$. Two other behavioral assumptions have gotten considerable attention in recent literature: 1) Hotelling-Smithies behavior where each entrepreneur believes his rivals' mill prices are fixed, and 2) Greenhut-Ohta behavior in which each entrepreneur believes the delivered price at his service area boundary is fixed. Let us briefly examine the implications of each entrepreneurial behavior assumption.

Assume that a new firm enters a product market at some distance from any existing firm (i.e., firm B entering in Figure 1). Nearby existing firms lose their most distant consumers. They will change their price as a result but their price change depends upon what they expect rivals' responses to be.

Figure 3 shows how the behavioral assumption affects each firm's pricing policy. Following entry the representative firm loses distant consumers and aggregate demand rotates in as in Figure 2. The Löschian competitor now views his service area as fixed. Consequently, this new aggregate demand is the demand perceived by a Löschian competitor (denoted by L in Figure 3). Thus, if the firm was initially charging $M_{0}$ in Figure 3, he will raise his price after losing his distant buyers (as in Figure 2), given he is a Löschian entrepreneur. The equilibrium Löschian price is represented by $M_{L}$ in Figure 3 .

A Hotelling-Smithies competitor does not feel his market is fixed. Instead, he believes his rivals will not change their prices. Thus, by lowering his price, the Hotelling-Smithies entrepreneur believes his service area will expand and he will be able to increase his quantity by more than the actual (Löschian) demand curve indicates. The initial demand perceived by a Hotelling-Smithies competitor (curve HS $\left(\mathrm{M}_{0}\right)$ in Figure 3 ) is more elastic than the Löschian demand so the Hotelling-Smithies competitor tends to lower his price. ${ }^{10}$ Since all entrepreneurs are assumed to have identical expectations, all spatial firms lower their prices. Instead of moving along the perceived $\mathrm{HS}\left(\mathrm{M}_{\mathrm{o}}\right)$ curve, all firms move along the actual demand curve (L), until some new equilibrium price is obtained $\left(\mathrm{M}_{\mathrm{HS}}\right.$ in Figure 3$)$. The entrepreneurs continue to believe that their demands are more elastic than the Löschian demand, however, so the 


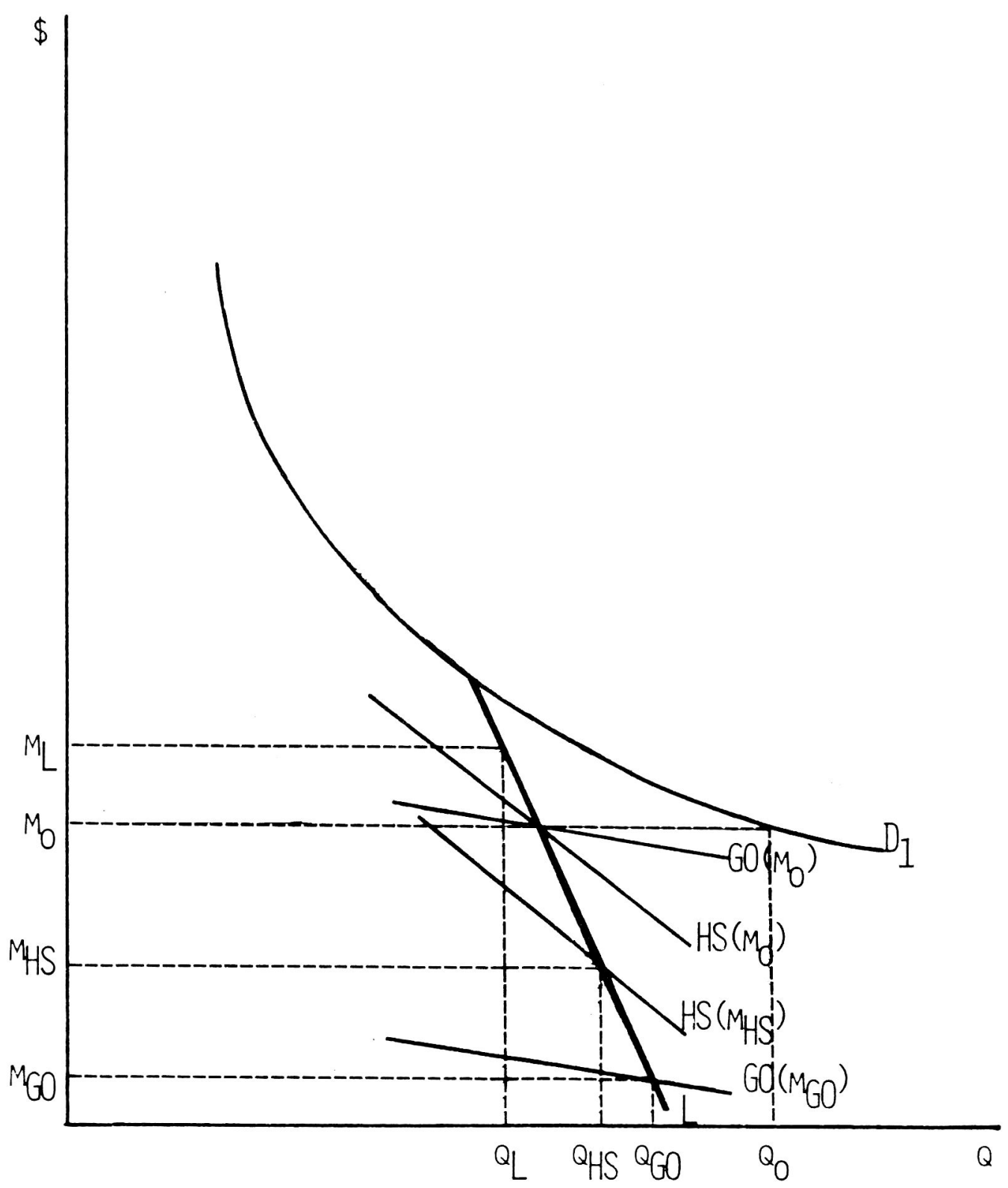

FIGURE 3:

DEMAND CURVES FOR ALTERNATIVE BEHAVIORAL ASSUMPTIONS.

graphical impact is that the perceived demand shifts down along the actual Löschian demand to the point where the equilibrium price is obtained $\left(\mathrm{HS}\left(\mathrm{M}_{\mathrm{HS}}\right)\right.$ ). (Note that this is the same as Chamberlin's monopolistic competition adjustment.) 
The argument is similar for Greenhut-Ohta competition except that the demand perceived by a Greenhut-Ohta entrepreneur is even more elastic than the demand perceived by a Hotelling-Smithies competitor $\left(\mathrm{GO}\left(\mathrm{M}_{0}\right)\right.$ in Figure 3 ). Consequently, by lowering his price the Greenhut-Ohta firm expects to capture even larger portions of rivals' service areas and expand quantity accordingly. Given that all entrepreneurs have the same expectations, the GO demand curve shifts down along the actual Löschian curve to a price even lower than the Hotelling-Smithies price $\left(\mathrm{M}_{\mathrm{GO}}\right.$ in Figure 3$)$.

What does all this have to do with the concentration to higher price to market power causality question? Assume free entry and a finite linear market space. Löschian competition leads to the highest short run profits of all three models of spatial competition [21]. Consequently it leads to the largest number of firms in the long run for any given (finite) geographic market space. Rather than derive the very complicated proof of this contention, we shall present the conclusions of Capozza and Van Order [11, 12] (and refer the reader to [21] for a more formal proof). Figure 4 shows the relationship between service area size (U) and mill price for the three entrepreneurial assumptions. $\mathrm{U}_{\max }$ is the maximum feasible service area size for a firm since, $\mathrm{U}>\mathrm{U}_{\max } \mathrm{im}$ plies that some consumers have negative net demands [11]. In other words, at $\mathrm{U}_{\max }, \mathrm{TU}=\mathrm{a}-\mathrm{M}$ from equation (3). ( $\mathrm{U}_{\max }=\mathrm{U}$ for a spatial monopolist).

In Figure 4 we also add a zero profit locus (ZPL). This ZPL implies that any $\mathrm{M}^{\prime}$, $\mathrm{U}$ pairing on the curve yields zero profits. The position of this curve is determined by the level of production costs. Therefore, if costs change this curve will move. The ZPL in Figure 4 is arbitrarily placed, then, with the assumption of some given level of costs. However, the shape of the ZPL (particularly the slope over the relevant range) does not change as we alter the level of costs. Therefore the conclusions which follow are general.

From Figure 4 we can see that, given free entry until profits disappear, the equilibrium Löschian mill price is greater than the Hotelling-Smithies mill price. Furthermore, the Hotelling-Smithies price exceeds the Greenhut-Ohta price. However, in the zero profit equilibrium Löschian firms have the smallest market area and Greenhut-Ohta firms have the largest, with Hotelling-Smithies falling in between. Thus, for a given finite space more Löschian firms are required to serve the entire space than Hotelling-Smithies firms, and more Hotelling-Smithies firms will exist than Greenhut-Ohta fïms. We can conclude that the type of spatial crompetition which yields the smallest (largest) number of firms also provides the lowest (highest) price.

Thus, there is an inverse relationship between price and concentration levels in spatial markets. That is, the higher the price charged by firms, the larger is the number of firms any given space can accommodate. This is the relevant conclusion of course. The point is that relatively high prices tend to be associated with relatively low levels of concentration in a spatial world. Thus, the existence of high levels of concentration does not necessarily imply high prices (nor high profits, since relatively high levels of concentration may simply im- 


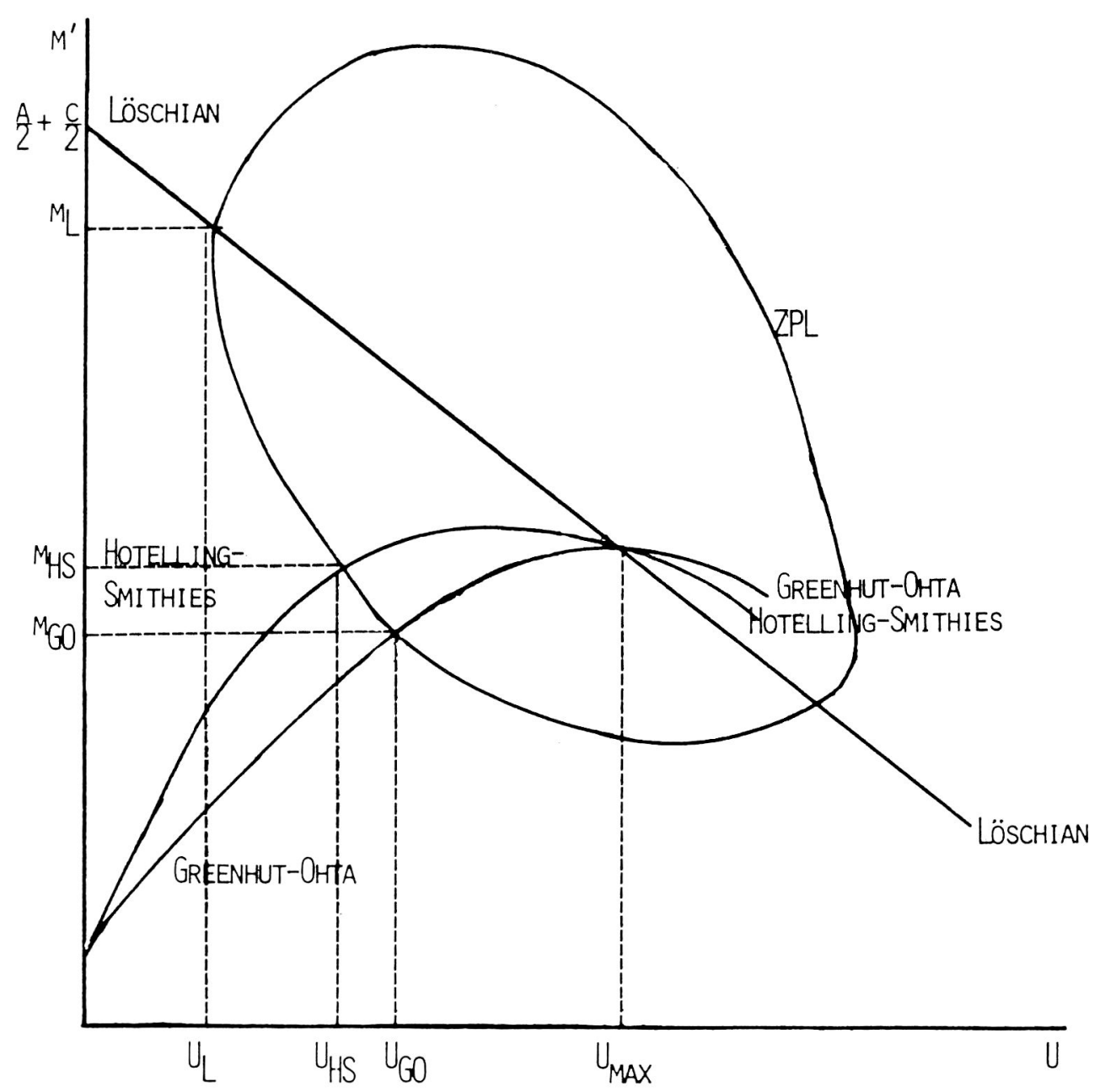

FIGURE 4:

\section{THE MILL PRICE-MARKET RADII LOCUS AND ZERO PROFIT EQUILIBRIUMS FOR ALTERNATIVE MODELS OF SPATIAL COMPETITION.}

ply Hotelling-Smithies or Greenhut-Ohta competition). In fact, causality may be reversed-a high price may imply low concentration.

The general contention is that concentration allows collusion. Therefore price rises and profits increase. The price charged by a Löschian competitor maximizes potential profits, however. Consequently, it is equivalent to the profit maximizing collusive price $[2,11]$. Therefore, Löschian spatial competitors will not raise price through collusion. On the other hand, HotellingSmithies or Greenhut-Ohta entrepreneurs would raise price through collusion (to the Löschian price). A relevant question then, is which type of behavior best fits the spatial entrepreneur? 
Hotelling-Smithies competition is the spatial equivalent of Chamberlin's monopolistic competition. That is, each firm assumes no other firm will react to his price change. Chamberlin's justification for this assumption was that each firm is so small relative to the market that the entrepreneur expects his pricing policy to go unnoticed. This is not the case in spatial competition even when there are a large number of firms involved. Chamberlin himself described the spatial market as linked oligopoly rather than monopolistic competition [13, pp. 103-104]. Each entrepreneur recognizes that nearby rivals are his major competitors. The entrepreneur realizes that these nearby firms not only notice his price changes; he also expects some response.

An essential feature of spatial competition is mutual interdependence. The primary effect of entry in a spatial world is that profits fall and firms become more cognizant of their competitors (rather than less as in monopolistic competition). Some recognition of and reaction to pricing policy must be expected. Greenhut-Ohta behavior implies a negative price response $[2,11]$. That is, if a Greenhut-Ohta firm raises (lowers) his price by $\mathrm{x}$ dollars he expects his rivals to lower (raise) their price by $\mathrm{x}$ dollars. However, all entrepreneurs are assumed to have identical behavior so prices actually move in the same direction. Thus, the Greenhut-Ohta (and Hotelling-Smithies) assumption implies that entrepreneurs do not recognize that their expectations are not being met in reality.

The Löschian assumption implies that firms expect their rivals to match any price change (this is what actually occurs in all three models). Chamberlin proposed a spaceless duopoly solution that depends upon mutual recognition of market interdependence [13, pp. 46-51]. He assumed that entrepreneurs, after realizing their interdependence, would set a monopoly price and share monopoly profits since this is the best they can do. Ferguson observed that "Chamberlin's solution has much to recommend it. Most important, his entrepreneurs behave in a sophisticated way in that they understand reality and act accordingly. This alone is a great improvement (over Cournot and Edgeworth models); but in addition he obtains a stable solution that is not too far from reality ..." [15, p. 313]. The same argument can be applied to Lösch's model of spatial competition. Löschian entrepreneurs "behave in a sophisticated way in that they understand reality and act accordingly." They recognize that the best they can expect is to split the geographic space into equal (or approximately equal) shares and profit maximize like a monopolist within their service area. Hotelling-Smithies and Greenhut-Ohta entrepreneurs, on the other hand, are extraordinarily naïve. The HotellingSmithies competitor believes his rivals will never change their prices, even though he repeatedly observes such changes. A Greenhut-Ohta entrepreneur expects rivals to change price in the opposite direction to that which he observes. Neither Hotelling-Smithies nor Greenhut-Ohta entrepreneurs ever learn. Thus, in Figure 3 the Löschian demand is the actual demand while the other models of spatial competition involve artifically adjusted curves which shift along the actual Löschian demand. 
Hotelling-Smithies or Greenhut-Ohta behavior may exist for some relatively short period. However, entrepreneurs should realize that their beliefs are incorrect after a few observations. The Löschian assumption can be restated as "firms recognize the actual demand situation they face and profit maximize accordingly" [2, p. 24]. This seems to be the best assumption (at least intuitively) to characterize spatial competitors over relatively long time periods. This is particularly true when any adjustments away from a Löschian price towards some Hotelling-Smithies or Greenhut-Ohta price lead to lower total profits [21, p. 11]. The Löschian price yields the highest possible profits given the number of locations.

Given that Löschian behavior characterizes spatial competitors, price will not rise as a result of collusion among these competitors-the competitive price equals the collusive price. This may seem to be an undesirable result. However, it need not be. The Löschian price is actually the socially optimal price in the long-run free entry equilibrium. We shall not prove this contention here since it is proven elsewhere (see [6]). However the efficiency conclusions result because, as previously noted, Löschian competition yields the highest profits. Therefore it attracts the most entrants. As a result, Löschian competition minimizes transportation costs for consumers and maximizes net consumer demand. So, Löschian behavior is undesirable only when there is not free entry. (The same can be said of collusive pricing of course.)

\section{THE IMPACT OF AN INCREASE IN CONCENTRATION AS A RESULT OF A MERGER OF SPATIALLY SEPARATED FIRMS}

Thus far we have assumed that all spatially separated firms are independently owned. Now consider a situation in which there are several spatially dispersed firms competing in the spatial sense (that is, competing at service area boundaries [5]). Each is charging a profit maximizing price over its service area and the firms are in an equilibrium (that is, no firm has any strong incentive to change its price). These firms are in a single competitive market even though all customers do not have access to each firm [5]. This results because of spatial competition. Since firms compete at their service area boundaries, any price change by one firm should cause a reaction by the other firms. For example, suppose firm A lowers his price and captures part of B's service area. Firm B should react with a lower price. B captures some of C's customers as a result and $\mathrm{C}$, in turn changes his price. Thus, in spatial competition price changes are transmitted over large geographic areas, as in a chain reaction. Competitive geographic markets tend to be large as a consequence [5].

Now let two of the firms merge. There has been a significant increase in ownership concentration. Will this merged firm raise its prices as a result? There are at least four reasons why price might change. First, increased concentration may increase the possibility of collusion. However, if the 
entrepreneurs are Löschian competitors before the merger then profits cannot be increased through a collusive price change. The merged firm's entrepreneur has the same goal as the independent firms had-profit maximization. The merger simply yields one firm with two separate submarkets - the requirement for effective price discrimination. The merged unit will want to charge the profit maximizing price in each of these submarkets. Since the independent firms were charging profit maximizing prices in their service areas before the merger, price will not change. Something besides changes in the level of concentration must occur in order for us to observe changes in price and output (unless spatial entrepreneurs are characterized by Hotelling-Smithies or Greenhut-Ohta behavior and profits can be increased by collusively setting a Löschian price).

The nature of spatial competition indicates that consumers obtain the same quantity at the same price whether all plants in a geographic space are independent, or all plants are owned, for example, by a few large holding companies. Any difference in price should not be due to changes in the degree of concentration in the geographic market. Either marginal cost or marginal revenue must change for the merged firm if price is to change in this spatial setting.

A second possible reason for a change in price is a change in costs. Demsetz [14] and Peltzman [22] argue that the concentration-profit causal relationship should typically run from concentration to costs to profits because of production efficiency. This is probably true in spatial competition (not necessarily however-see below). If the merger involves scale economies then the merged firm will change its prices. However, the firm's prices will fall as profits rise [1]. Price may rise of course, if there are diseconomies of scale.

There is a possibility of an increase in price as a result of the above merger. Consumers may view a multi-location firm's product as more desirable than a single location firm's product. For example, if these firms are banks a consumer may prefer a banking organization with multiple branches (perhaps with branches near shopping areas, one near his place of residence, and one near his place of business, for instance) over a unit bank. In this case the demand for the multi-location firm's product is relatively strong. Thus, when two firms merge demand for their product may increase relative to the demand for other non-merged firms' product. Consequently, the merged firm raises its price. However, this is a result of stronger consumer preferences, not of increased market power due to concentration. Causation runs from stronger demand for the product of a multi-location firm to higher prices to higher profits. This is not an undesirable result, however, since prices rise in response to an increase in demand. There may be a correlation between concentration, prices, and profits, but as Demsetz observed [14], correlation does not imply causation.

A fourth reason for changing prices following a merger is that there may be a redistributional impact, given that the spatial distribution of inputs and outputs differ. For example, consider the merger of spatially separated banks 
again. Suppose deposits are relatively abundant at one of the merged firm's location, and that they are relatively scarce at the other firm's site. The first bank's loan rate would be relatively high before the merger, but with the merger we would expect that rate to fall while the loan rate at the second bank rises. Before the merger borrowers at the first bank would not be able to take advantage of relatively low rates at the second bank because of transportation costs. The bank with scarce deposits would not be able to attract funds from the other bank's depositors because it would have to pay a very high interest rate to cover depositor's costs of distance. In other words, distance costs are very high for consumers and for independent banks. However, when the banks merge the multi-unit bank can easily transfer funds in order to maximize profits. As this transfer takes place rates will tend to equate at the two locations. This transfer between various locations of a multi-unit system is desirable of course. Economic efficiency, in the sense of maximizing production of goods and services, is served by allocating funds to where they earn the highest return. This reallocation would be accompanied by rising and falling prices at different sites, however.

Some economic forces may cause price to rise following a merger (i.e., relatively strong demand for the product of a multi-location firm) and others may have a downward pressure on price (i.e., scale economies). Still other forces may cause prices at one site to rise while others fall. None of these price changes need to have anything to do with concentration and collusion, and in a spatial setting it appears likely that they do not.

\section{SUMMARY AND CONCLUSIONS}

A direct correlation between concentration and price is possible in a spatial setting. However, an inverse relationship is also theoretically explainable. The actual relationship for any one industry will depend upon the type of spatial competition which exists in the industry, the value consumers place on the availability of the product of a single firm with multiple locations (and the existence of multi-location firms), the existence of scale economies (or diseconomies), as well as other characteristics of consumer demand and firm costs. ${ }^{11}$ It is not surprising that empirical studies find only weak correlation between concentration and price, especially in studies which use several industries or two and three digit FIC classifications. There are probably economic forces which tend to push price up in some industries and down in others as the level of concentration increases. In fact, there are forces working in both directions within single industries. ${ }^{12}$

There may be a relationship between concentration of ownership and profits in a spatial setting. However, if it is a causal relationship it probably runs from concentration to costs to profits. Price can rise as a result of a merger of spatially separated firms but the price increase generally reflects consumer preferences for the product of a multi-location firm rather than collusion. This is particularly true when Löschian behavior characterizes spatial 
entrepreneurs because the spatially competitive price is identical to a collusive price. (It also happens to be the socially most desirable price given free entry [6].)

The general assumption that concentration of ownership is a proxy for market power because of the concentration to (high collusive) price to profits causal relationship is not valid in a spatially competitive industry. Of course, when transportation costs are insignificant and/or when consumers or producers are not spatially distributed, the conclusions reached here do not apply. (How many industries are there in which space is irrelevant?) We can say, however, that spatial competition is very significant in some industries that are highly regulated and/or closely scrutinized by the Antitrust Division. For example, spatial competition is important in the banking industry [1]. Furthermore, over half of the Department of Justice's merger litigations between 1960 and 1972 were devoted to banking [19]. Concentration ratios were used to measure the competitive impact of these mergers. However the concentration ratios used were generally meaningless for several reasons (only some of which are discussed here $\left.{ }^{13}\right)$. The important consideration for spatial competition is the number of locations available to the consumer, not the ownership of those locations. An increase in the number of locations increases the level of spatial competition even if the new location is owned by a firm that has another (or several other) plants at different points in space.

\section{FOOTNOTES}

1. Concentration ratios are used for the same purpose by other regulatory authorities concerned with mergers (for example, the Comptroller of the Currency, the Federal Reserve Board, and the FDIC with respect to bank mergers).

2. See, for example, Brozen's examination of some of the most influential empirical studies $\mid 7,8$, 9]

3. The term "concentration" is used here to mean concentration of ownership rather than a spatial concentration of economic activity.

4. Some implications of spatial prices theory for the concentration-competitive performance relationship have already been noted. See Benson [1], and Ohta [21].

5. Note, in addition, that spatial price theory has significant implications for the delineation of competitive geographic markets [5]. Generally regulators have not accounted for spatial competition in delineating the relevant geographic market. Consequently, concentration ratios may be meaningless even if there is a concentration to price to profit relationship.

6. We have, in effect, specified the relative changes in supply and demand by assuming the shape of individual demand, and of each firm's marginal cost [2]. Another specification of either can alter this result $\{2,3\}$. However, the point is that entry and reduced concentration can cause higher prices.
7. Actually the price determining process is very different in spatial and spaceless competition. Spaceless competitors are price takers but spatial competitors are always interdependent price setters [16]. The above discussion of the supply and demand impacts of the entry of spatial firms is meant to provide an intuitive feeling for the price result. For a discussion of the difference between spatial and spaceless price determination see [4].

8. We refer to the geographic area over which a firm sells as a service area in order to distinguish this space from the competitive geographic market area. It is demonstrated elsewhere that the competitive market and the firm's market are two different concepts in spatial competition [5].

9. The assumption was proposed by Lösch [18], and formalized by Mills and Lav [20]. For a discussion of the implications of the assumption see $[2,3,6]$.

10. Actually Hotelling-Smithies entrepreneurs may either raise or lower price, depending upon the size of the market area and the firm's cost functions [11]. However, Capozza and Van Order argue that the "normal" reaction is to lower price [11].

11. The shape of the individual demand function is relevant, for example $[2,3,21]$.

12. In banking, for example, spatial competition is 
significant [1], and as seen above, many factors affect price following a merger. The correlation between concentration and price is, consequently, very weak. For a brief discussion of the empirical evidence and spatial implications see [1].

13. See [1] for other implications of spatial microeconomics for the concentration-market power relationship. For example, when consumers are not evenly distributed relatively large firms will produce in areas of high population density while small firms produce in low density areas. This is true even in a zero profit equilibrium. This concentration is not related to market power or profits then. It simply reflects the spatial distribution of consumers.

Furthermore, the Antitrust Division typically does not account for the implications of spatial competition for market area delineation [5]. Consequently they tend to define their competitive geographic markets to be smaller than the actual competitive market. This overstates the anticompetitive impact, given the use of concentration ratios.

\section{REFERENCES}

1. Benson, B. "An Examination of U.S. v. Philadelphia National Bank in the Context of Spatial Microeconomics." Industrial Organization Review 8 (1980): 27-65.

2. "Are the Conclusions of Löschian Spatial Competition Really Counter-Intuitive?" Working Paper No. 5-79-1. The Pennsylvania State University. May 1979.

3. "Löschian Competition Under Alternative Demand Conditions." American Economic Review 70 (December 1980) 1098-1105.

4. _The Impact of Entry at a Distance on Market Demand." Review of Regional Studies (forthcoming).

5. "Spatial Competition: Implications for Market Area Delineation in Antimerger Cases." The Antitrust Bulletin 25 (Winter 1980): 729-749.

6. "The Optimal Size and Number of Market Areas." Southern Economic Journal 47 (April 1981): 1080-1085.

7. Brozen, Y. "Bain's Concentration and Rates of Return Revisited." Journal of Law and Economics, 14 (October 1971): 351-370.

8. "Concentration and Structural and Market Disequilibria." Antitrust Bulletin, 16 (Summer 1971): 241-248.

9. centration Recommendation." Journal of Law and Economics, 13 (October 1970): 279-292.

10. Capozza, D. and K. Attaran. "Pricing and Spatial Dispersion of Firms Under Free Entry." Journal of Regional Science, 16 (August 1976): 167-182.

11. and R. Van Order. "A Generalized
Model of Spatial Competition." American Economic Review, 68 (December 1978): 896-908.

12. and "Pricing Under Spatial Competition and Spatial Monopoly." Econometrica, 43 (September 1977): 1329-1338.

13. Chamberlin, E. The Theory of Monopolistic Competition, 8th Edition. Cambridge, Mass.: Harvard University Press, 1933.

14. Demsetz, H. "Industry Structure, Market Rivalry, and Public Policy," Journal of Law and Economics, 16 (April 1973): 1-9.

15. Ferguson, C. Microeconomics Theory. Homewood, Ill.: Richard D. Irwin, Inc., 1969

16. Greenhut. M. A Theory of the Firm in Economic Space. Austin, Tx.: Austin Press, 1971.

17. , M. Mwang and H. Ohta. "Observations on the Shape and Relevance of the Spatial Demand Function." Econometrica, 43 (July 1975): 705-713.

18. Losch, A. The Economics of Location. New Haven: Yale University Press, 1954.

19. Metzger, E. "Legislation, Regulation, Antitrust, and Bank Mergers-A Reply." Banking Law Journal, 92 (May 1975): 427-436.

20. Mills, E. and R. Lav. "A Model of Market Area with Free Entry." Journal of Political Economy, 72 (June 1964): 278-288.

21. Ohta, H. "Spatial Competition, Concentration and Welfare." Regional Science and Urban Economics, 10 (March 1980): 3-16.

22. Peltzman, S. "The Gains and Losses From Industrial Concentration." Journal of Law and Economics, 20 (October 1977): 229-263. 